\title{
Avaliação Microbiológica do Fruto In Natura de Diferentes Cultivares de Morangueiro
}

\author{
Amanda G. Guimarães, Valter C. A. Júnior, Cíntia G. Guimarães, \\ Tiago J. Guedes \& Nísia A. V. D. Pinto
}

O objetivo deste estudo foi avaliar a microbiologia dos frutos in natura de diferentes cultivares de morangueiro. Os morangos in natura das oito cultivares foram avaliados quanto aos coliformes totais, bolores e leveduras e aeróbios mesófilos em três épocas de colheita. Não foi detectada a presença de coliformes totais em nenhuma das oito cultivares de morangueiro. Apesar da maior ocorrência de aeróbicos mesófilos para cultivar Aromas e as altas quantidades de bolores e leveduras para cultivar Toyonoka, estes resultados foram menores que encontrados na literatura, o que pressupõe a dizer que os morangos foram cultivados com uma boa prática agrícola.

Palavras-chave: Fragaria x ananassa Duch; bolores e leveduras; qualidade.

The aim of this study was to evaluate the microbiology of fruits in natura of different cultivars of strawberry. The strawberries in natura eight cultivars were evaluated for total coliforms, molds and yeasts and mesophilic aerobic three harvest seasons. There were detected the presence of total coliforms in any of the eight strawberry cultivars. Despite the higher incidence of mesophilic aerobic to cultivate Aromas and the high amount of molds and yeasts to grow Toyonoka, these results are lower than in the literature, which presumes to say that strawberries were grown on good agricultural practice.

Keywords: Fragaria x ananassa Duch; yeasts and molds; quality. 


\section{Introdução}

O morangueiro (Fragaria $\mathrm{x}$ ananassa Duch), pertencente da família das rosáceae, é apreciado em muitos países por apresentar características sensoriais atrativas e nutricionais bem definidas, sendo assim, sua comercialização in natura, processada ou congelada ${ }^{1,2}$. A cultura se destacada também pela alta rentabilidade por área e demanda intensa de mãode-obra familiar o que contribui para a geração de renda para os pequenos agricultores ${ }^{3}$.

Embora seja uma cultura economicamente importante, são poucas as informações disponíveis quanto aos aspectos microbiológicos pós-colheita dos morangueiros. Esta caracterização é importante para verificar quais e quantos micro-organismos estão presentes, além de conhecer se a microbiota altera de cultivar para cultivar utilizada no cultivo. A presença de micro-organismos em números reduzidos em frutos, não significa risco para o consumidor ou uma qualidade inferior. Porém se os princípios de higienização e de higiene foram violados, além dos frutos estiverem em condições que permitem a entrada e/ou crescimento de agentes infecciosos podem se tornarem um veículo e/ou substrato para a multiplicação de diversos micro-organismos ${ }^{4,5}$.

Os frutos de morangos possuem a camada externa fina, sendo altamente pere $\neg$ cível por possuir rápida perda de água nos seus tecidos em função da alta taxa respiratória 6 , podendo acarretar uma baixa conservação in natura e consequentemente suscetível a incidência de micro-organismos tendo perdas tantos nutritivas quanto econômicas ${ }^{7,8}$. Conforme o tipo de cultivar de morangueiro e as condições do ambiente estas perdas podem ocorrer em apenas 48 horas depois de colhido ${ }^{9}$.

É indispensável também verificar se os padrões e especificações quanto aos aspectos microbiológicos para alimentos, nacionais ou internacionais, estão sendo atendidos adequadamente ${ }^{10}$. Assim, a microbiota normalmente presente constitui-se em bolores, leveduras, bactérias lácticas e outros micro-organismos ácido tolerantes como bactérias acéticas, Zymomonas e algumas espécies de Bacillus ${ }^{11}$. Esses micro-organismos quando presentes nos alimentos podem fornecer a ocorrência de contaminação, sobre provável presença de patógenos ou sobre a deterioração potencial dos alimentos, além de indicarem condições sanitárias inadequadas durante o processamento, produção ou armazenamento ${ }^{10}$.
Com isso, é importante avaliar se diferentes cultivares de morangueiro possam resultar em alterações quanto às avaliações microbiológicas, já que cada cultivar tem sua genética própria e possui aspectos físico-químicos diferentes. Então, o objetivo deste trabalho foi de avaliar a qualidade de frutos in natura de diferentes cultivares de morangueiro quanto as análises microbiológicas.

\section{Materiais e Métodos}

\section{MATERIAL VEGETAL}

As mudas das oitos cultivares de morangueiro (Festival, Campinas, Toyonoka, Dover, Oso Grande, Camarosa, Diamante e Aromas) foram doadas pela Empresa Multiplanta Biotecnologia Vegetal Ltda. As mudas foram multiplicadas e os morangos produzidos na empresa Mape Frutas Ltda, localizada no município de Datas, Minas Gerais ( $18^{\circ} 26^{\prime}$ latitude S, 43 $39^{\prime}$ longitude $\mathrm{W}$, a $1.244 \mathrm{~m}$ de altitude). O clima é tropical úmido Aw, na classificação de Köppen, com uma estação seca no inverno e estações chuvosas no verão, e o solo foi classificado como Neossolo quartzarênico.

As mudas de morangueiro foram cultivadas em delineamento experimental de blocos casualizados, com oito cultivares e quatro repetições ${ }^{12}$. As parcelas experimentais foram compostas por dezoito plantas espaçadas de 30x30cm, com área útil de dois metros quadrados. O plantio deu-se em março de 2012 sob cultivo protegido em túnel baixo coberto com plástico de 75 micras de espessura com altura de $80 \mathrm{~cm}$ da superfície do canteiro. O canteiro foi coberto com plástico ("mulching") branco de trinta micras, com 20 $\mathrm{cm}$ de altura, $64 \mathrm{~m}$ de comprimento e $1 \mathrm{~m}$ de largura. A fertirrigação foi realizada por meio de tubos gotejadores e os tratos culturais recomendados pela cultura. Os frutos, para a caracterização microbiológica, foram colhidos manualmente no estágio a $75 \%$, em junho, agosto e outubro de 2012 , com temperaturas médias de $14,83{ }^{\circ} \mathrm{C}$, $16,75^{\circ} \mathrm{C}$ e $19,37^{\circ} \mathrm{C}$, respectivamente.

\section{DELINEAMENTO EXPERIMENTAL}

Para as análises microbiológicas, considerou-se o delineamento experimental inteiramente ao acaso, com parcelas subdivididas no tempo, sendo as cultivares 
a parcela principal e a época de colheita a subparcela. Desta forma, o modelo estatístico foi:

$$
\text { Yijk }=m+g i+e i j+c k+g c i k+d i j k,
$$

em que: Yijk = observação referente à k-ésima colheita, da i-ésima cultivar; $\mathrm{m}=$ média geral; gi = efeito da i-ésima cultivar $(i=1,2, \ldots, 8)$ assumido como fixo; eij = efeito da interação entre a i-ésima cultivar e o j-ésimo repetição $(1,2,3)$ (erro A); ck = efeito da k-ésima colheita $(\mathrm{k}=1,2, \ldots, \mathrm{K})$ assumida como fixo; gcik =efeito da interação entre a i-ésima cultivar e a k-ésima colheita assumida como fixo; dijk = efeito da interação entre a k-ésima colheita, j-ésimo repetição e i-ésima cultivar assumido como aleatório (erro B).

\section{ANÁLISES MICROBIOLÓGICAS}

As análises microbiológicas foram conduzidas no Laboratório de Tecnologia Biomassa do Cerrado, da Universidade Federal dos Vales do Jequitinhonha e Mucuri (UFVJM), no Campus JK, em Diamantina, Minas Gerais. Para cada época de colheita, uma mistura dos morangos das parcelas foi colhida e pesada, perfazendo um total de 25 gramas de cada cultivar. Retiraram-se os pecíolos e sépalas dos frutos e estes foram lavados em água destilada, simulando a maneira do consumo dos consumidores. Para a metodologia das análises microbiológicas, os morangos foram transferidos para bolsas esterilizadas e homogeneizados em $225 \mathrm{~mL}$ de solução de cloreto de sódio $0,85 \%$. Em seguida, foram realizadas diluições decimais seriadas (10-1, 10-2 e 10-3) em solução de cloreto de sódio $0,85 \%$, em triplicata para verificar as seguintes análises:

- Coliformes totais (CT), com o uso de Petrifilms EC $3 \mathrm{M} \AA$, nos quais uma alíquota de $1 \mathrm{~mL}$ de amostra foi aplicada perpendicularmente ao gel na base do petrifilm. Foram incubados a $35 \pm 2$ ${ }^{\circ} \mathrm{C}$ por 48 h. Os resultados foram expressos por logaritmo da contagem microbiana (média de três repetições) em Unidades Formadoras de Colônia por grama de material $(\log \mathrm{UFC} g-1)^{13}$.

- Bolores e leveduras (BL), determinadas pelas contagens utilizando o método de plaqueamento direto em superfície em meio Ágar Batata Dextrose (BDA), acidificado com solução de ácido tartárico a $10 \%{ }^{14}$. Alíquotas de $100 \mu \mathrm{L}$ foram semeadas na superfície do Agar e as placas foram incubadas a $25 \pm 2{ }^{\circ} \mathrm{C}$ por 5 dias. A contagem para os cálculos é significativa quando predomina nas placas entre 25 e 300 colônias. Os resultados foram calculados por logaritmo da contagem microbiana (média de três repetições) e expressos em Unidades Formadoras de Colônia por grama de material $(\log \text { UFC g- } 1)^{13}$.

- Aeróbios mesófilos totais (AM), determinados pelas contagens pelo método semeadura em profundidade em Ágar Padrão para Contagem (PCA), com incubação a $35 \pm 2{ }^{\circ} \mathrm{C}$ por 2 dias 15. A contagem para os cálculos é significativa quando predomina nas placas entre de 25 a 300 aeróbicos mesófilos. Os resultados foram calculados por logaritmo da contagem microbiana (média de três repetições) e expressos em Unidades Formadoras de Colônia por grama de material $\left(\log\right.$ UFC g-1) ${ }^{13}$.

Após a análise de variância, quando identificada significância a $5 \%$ de probabilidade pelo teste $\mathrm{F}$ para os efeitos de cultivar, colheita e interação (cultivar $\mathrm{x}$ colheita) foi feita a comparação entre as médias pelo teste Tukey pelo programa computacional Genes ${ }^{16}$.

\section{Resultados e Discussão}

Não foi detectada a presença de coliformes totais em níveis significativos nos frutos de nenhuma das cultivares de morangueiro. Isto pode ser atribuído ao emprego de boas práticas agrícolas, já que os coliformes totais avaliam as condições higiênicas do produto, pois, quando em alto número, indica contaminação decorrente de falha durante o processamento, limpeza inadequada ou tratamento térmico insuficiente ${ }^{17,14}$. Além disso, a presença de ácidos orgânicos na composição do morango, principalmente, ácido cítrico, confere condição inóspita ao desenvolvimento do grupo coliforme ${ }^{18}$. A Resolução da Diretoria Colegiada (RDC) n n .12, de 02 de janeiro de $2001^{19}$ estabelece para frutas frescas, in natura, preparadas (descascadas ou selecionadas) sanificadas, refrigeradas ou congeladas, para consumo direto, o limite máximo para amostra indicativa de 5x102 UFC g-1 para coliformes, e que quantidades superiores a estas podem apresentar perdas no valor nutricional, alterações sensoriais, riscos de deterioração e/ou presença de patógenos o que os torna impróprios para o consumo ${ }^{20}$. 
As fontes de variação: cultivares de morangueiro e a época da colheita apresentaram diferenças significativas $(\mathrm{p}<0,05)$ para as outras duas variáveis avaliadas, aeróbicos mesófilos totais e bolores e leveduras (Tabela 1). A fonte de variação, interação cultivar e época da colheita também foram significativas para ambas as características, o que leva a concluir que as cultivares resultaram diferentes respostas à época que foi realizada a colheita. Esta diferença é observada na Tabela 2.

Tabela 1. Resumo da análise de variância em blocos ao acaso em esquema de parcela subdividida no tempo, das características: aeróbicos mesófilos (AM) e bolores e leveduras (BL) de cultivares de morangueiro e épocas de colheitas

\begin{tabular}{|c|c|c|c|}
\hline \multicolumn{2}{|c|}{ FV } & GL & \multicolumn{2}{c|}{ Quadrado médio } \\
\hline \multicolumn{2}{|c|}{} & AM & BL \\
\hline Cultivar & 14 & $4,84^{*}$ & $1,08^{*}$ \\
\hline Erro 1 & 2 & 0,00 & 0,00 \\
\hline $\begin{array}{c}\text { Época colheita } \\
\text { Cultivar x época } \\
\text { colheita }\end{array}$ & 14 & $0,02^{*}$ & $0,10^{*}$ \\
\hline Erro 2 & 32 & 0,00 & $0,04^{*}$ \\
\hline CV 1(\%) & & 0,91 & 1,73 \\
\hline CV 2(\%) & & 1,21 & 2,22 \\
\hline
\end{tabular}

* significativos $5 \%$ de probabilidade pelo teste $\mathrm{F}$; ns: não significativo pelo teste $\mathrm{F}$
A alta ocorrência de bactérias aeróbicas mesófilos totais é um dos indicadores microbiológicos da qualidade dos alimentos, além da informação sobre a alteração incipiente dos alimentos e sua provável vida útil (ICMF, 1984). Foi observada em maior quantidade na cultivar Aromas (5,41 log UFC g-1) e a menor ocorrência foi a Toyonoka (3,09 log UFC g-1) (Tabela 2), isso pode ser devido à própria genética e o teor de umidade diferentes em cada cultivar, o que favorece o crescimento deste tipo de micro-organismos ${ }^{21}$. Já que na mesma época das colheitas dos frutos, Guimarães 1 avaliaram estas mesmos cultivares quanto aos aspectos físico-químicos e observaram que a cultivar Aromas teve em média um teor de umidade de $91,87 \%$ enquanto que a cultivar Toyonoka foi de $87,91 \%$. Confrontando com os trabalhos de Ponce ${ }^{22}$, obtiveram valores de aeróbicos mesófilos totais em morango abaixo apenas da cultivar Aromas, com 5,2 $\log \mathrm{UFC} \mathrm{g}^{-1}$. A época de colheita que mais detectou a presença de bactérias aeróbica mesófilos total foram as que tiveram maior temperatura (agosto e outubro). A Resolução da Diretoria Colegiada (RDC) $\mathrm{n}^{\circ}$. 12, de 02 de janeiro de 2001 19, ainda não estabelecem parâmetros para contagem padrões em placas para aeróbicos mesófilos.

Tabela 2 Contagem de aeróbicos mesófilos totais e bolores e leveduras de frutos de diferentes cultivares de morangueiro em três épocas de colheita

\begin{tabular}{|c|c|c|c|c|c|c|c|c|}
\hline \multirow[b]{3}{*}{ Cultivares* } & \multicolumn{4}{|c|}{ Aeróbicos mesófilos totais (log UFC g-1) } & \multicolumn{4}{|c|}{ Bolores e Leveduras $\left(\log \mathrm{UFC} \mathrm{g}^{-1}\right)$} \\
\hline & \multicolumn{3}{|c|}{ Épocas de colheita* } & \multirow[b]{2}{*}{ Média } & \multicolumn{3}{|c|}{ Épocas de colheita* } & \multirow[b]{2}{*}{ Média } \\
\hline & Junho & Agosto & Outubro & & Junho & Agosto & Outubro & \\
\hline Aromas & $5,50 \mathrm{Aa}$ & $5,44 \mathrm{Aa}$ & $5,28 \mathrm{Ab}$ & $5,41 \mathrm{~A}$ & $3,46 \mathrm{Cb}$ & 3,52 CDab & $3,60 \mathrm{Ca}$ & $3,53 \mathrm{C}$ \\
\hline Camarosa & $3,91 \mathrm{Da}$ & 3,86 Eab & $3,82 \mathrm{~Eb}$ & $3,86 \mathrm{D}$ & $3,90 \mathrm{Bb}$ & $3,88 \mathrm{Bb}$ & $4,01 \mathrm{Ba}$ & $3,93 \mathrm{~B}$ \\
\hline Campinas & $3,40 \mathrm{~Eb}$ & $3,50 \mathrm{Fa}$ & $3,48 \mathrm{Fa}$ & $3,46 \mathrm{E}$ & $3,52 \mathrm{Ca}$ & $3,45 \mathrm{DEa}$ & $3,50 \mathrm{CDa}$ & $3,49 \mathrm{CD}$ \\
\hline Diamante & $4,61 \mathrm{Ba}$ & $4,55 \mathrm{Ba}$ & $4,40 \mathrm{Bb}$ & $4,52 \mathrm{~B}$ & $3,51 \mathrm{Ca}$ & $3,47 \mathrm{DEa}$ & $3,50 \mathrm{CDa}$ & $3,49 \mathrm{CD}$ \\
\hline Dover & $4,09 \mathrm{Cb}$ & $4,28 \mathrm{Ca}$ & 3,93 Dc & $4,10 \mathrm{C}$ & $3,45 \mathrm{Cb}$ & $3,62 \mathrm{Ca}$ & $3,20 \mathrm{Ec}$ & $3,42 \mathrm{D}$ \\
\hline Festival & $4,06 \mathrm{Ca}$ & 4,07 Da & $4,07 \mathrm{Ca}$ & $4,06 \mathrm{C}$ & $3,44 \mathrm{Cb}$ & $3,62 \mathrm{Ca}$ & $3,40 \mathrm{Db}$ & $3,49 \mathrm{CD}$ \\
\hline Oso Grande & $3,41 \mathrm{~Eb}$ & $3,28 \mathrm{Gc}$ & $3,50 \mathrm{Fa}$ & $3,39 \mathrm{~F}$ & $3,27 \mathrm{Da}$ & $3,47 \mathrm{Ea}$ & $3,03 \mathrm{Fb}$ & $3,21 \mathrm{E}$ \\
\hline Toyonoka & $3,12 \mathrm{Fa}$ & $3,02 \mathrm{Hb}$ & $3,13 \mathrm{Ga}$ & $3,09 \mathrm{G}$ & $4,20 \mathrm{Ab}$ & 4,43 Aa & $4,22 \mathrm{Ab}$ & $4,32 \mathrm{~A}$ \\
\hline Média & $3,95 \mathrm{~b}$ & $4,00 \mathrm{a}$ & $4,01 \mathrm{a}$ & 3,99 & $3,61 \mathrm{~b}$ & $3,67 \mathrm{a}$ & $3,56 \mathrm{~b}$ & 3,61 \\
\hline
\end{tabular}

* significativo a 5\% de probabilidade pelo teste F. Médias seguidas pela mesma letra minúscula na linha e maiúscula na coluna não diferem entre si pelo teste de Tukey $(\mathbf{p}<\mathbf{0 , 0 5})$ 
Os bolores e leveduras são fungos podendo estar presentes no solo, ar, água e em matéria orgânica, e sua presença fornece informações das condições higiênicas deficientes em equipamentos e matéria prima com contaminação excessiva ${ }^{23}$. $\mathrm{O}$ aparecimento de bolores e leveduras nos morangos era de se esperar, devido o pH ácido 1,25. A maior ocorrência de bolores e leveduras foi observada na cultivar Toyonoka $(4,32$ $\log$ UFC g-1) e a menor a cultivar Oso Grande $(3,21$ $\log$ UFC g-1) (Tabela 2). Estes resultados têm forte ligação nas características físico-químicas de cada cultivar, principalmente, porque os bolores e leveduras conseguem se multiplicar em alimentos com baixa textura, além da baixa umidade e altas concentrações de açúcar ${ }^{21}$. Isso é confirmado nos trabalhos de Andrade ${ }^{7}$ avaliaram estas mesmas cultivares quanto à textura, a Toyonoka apresentou menor firmeza $(4,6$ N) o que pode ter facilitado a entrada destes fungos, enquanto que a cultivar Oso Grande apresentou maior firmeza $(6,5 \mathrm{~N})$. Nos trabalhos de Guimarães 1 , nas mesmas épocas de colheitas e nas mesmas cultivares, encontraram a maior quantidade de sólidos solúveis $\left(8,68{ }^{\circ}\right.$ Brix $)$ e açúcares redutores totais (6,84 g 100g-1) para a cultivar Toyonoka e menores respectivamente para a cultivar Oso Grande, com 6,08 ${ }^{\circ}$ Brix e 4,98 g $100 \mathrm{~g}-1$. A época de colheita que mais detectou os bolores e leveduras foi o mês de agosto (3,67 log UFC g-1). Os resultados deste trabalho apresentaram baixos valores de bolores e leveduras se comparados com os trabalhos de Moraes ${ }^{24}$, Ponce ${ }^{22} \mathrm{e}$ Nascimento e Silva ${ }^{25}$ encontraram 4,38 log UFC g-1, 5,8 log UFC g-1 e 4,61 log UFC g-1 em morangos, respectivamente.

No Brasil, não existe legislação específica que estabeleça limites permitidos para bolores e leveduras em frutos. Mas, quando encontradas contagens elevadas, tornam-se uma preocupação no âmbito da saúde pública, porque algumas espécies de fungos são produtoras de micotoxinas podendo gerar danos à saúde humana ${ }^{10}$. Brackett ${ }^{26}$ relatou a contaminação microbiana em vegetais de até $6,0 \log$ UFC g-1. Já Vitti ${ }^{27}$ consideram que, acima de $5 \log$ UFC g-1, são impróprios para o consumo humano com perdas no valor nutricional, alterações sensoriais, riscos de deterioração e/ou presença de patógenos ${ }^{20}$.

\section{Conclusões}

Não foi detectada a presença de coliformes totais em nenhuma das oitos cultivares de morangueiro. Apesar da maior ocorrência de aeróbicos mesófilos para a cultivar Aromas e as altas quantidade de bolores e leveduras para cultivar Toyonoka, estes resultados são menores que encontrados na literatura, o que pressupõe a dizer que os morangos foi cultivados em boa prática agrícola.

\section{Agradecimentos}

Á FAPEMIG e Capes, pelas bolsas e recursos disponibilizados para o desenvolvimento do projeto; à empresa Multiplanta Biotecnologia Vegetal Ltda., pela doação das matrizes de morangueiro; à empresa Mape Frutas Ltda., pela concessão da área experimental e pelo apoio na condução do projeto.

\section{Referências}

1. Guimarães, A. G.; Andrade Júnior, V. C.; Azevedo, A. M.; Guedes, T. J.; Pinto, N. A. V. D. Fruits 2016, 151.

2. Oliveira, C. M.; Gonçalves, A.; Vieira, G.; Dessimoni, N. A. V. 2010. Revv Bras. Armazenamento, 2010, 35, 107.

3. Gimenez, G.; Andriolo, J.; Godoi, R. Cienc. Rural 2008, 38, 273.

4. Gonçalves, P. M. R. Higiene Alimentar 1998, 12, 38.

5. International commission on microbiological specifications for foods (ICMF). Microorganismos de los alimentos: técnicas de analisis microbiológico. Zaragoza: Acribia, 1984.

6. Mirahmadi, F.; Hanafi, Q. M.; Alizadeh, M.; Mohamadi, H.; Sarsaifee, M. Afr. J. Food Sci. Technol. 2011, 2, 109.

7. Andrade júnior, V. C.; Guimarães, A. G.; Azevedo, A. M.; Pinto, N. A. V.D.; Ferreira, M. A. M. Hortic. Bras. 2016, 34, 405.

8. Reis, K. C.; Sinqueira, H. H.; Alves, A. P.; Silva, J. D.; Lima, L. C. O. Ciênc. Agrotec. 2008, 32, 196.

9. Ronque, E. R. V. A cultura do morangueiro. Emater: Paraná, 1998.

10. Franco, B. D. G. M.; Landgraf, M. Microbiologia de Alimentos. Atheneu: São Paulo, 2003.

11. Siqueira, R. S.; Borges, M. F. Microbiologia de frutos e produtos derivados. Embrapa/CTAA: Rio de Janeiro, 1997.

12. Guimaraes, A. G., Andrade Júnior, V. C. D., Elsayed, A. Y. A. M., Fernandes, J. S. C., \& Ferreira, M. A. M. Ver. Bras. Frutic. 2015, $37,112$.

13. American Public Health Association (APHA). Compendium of Methods for the Microbiological Examination of Foods, 4th ed., Washington DC: Frances Pouch Downes \& Keith Ito, 2001. 
14. Silva, N.; Junqueira, V. C.; Silveira, N. F. A. Manual de métodos de análise microbiológica de alimentos. 2th. ed., Varela: São Paulo, 1997.

15. Morton, R. D. Compendium of Methods for the Microbiological Examination of Foods, 4th ed., American Public Health Association: Washington DC., 2001.

16. Cruz, C. D. Acta Sci. Agron. 2013, 35, 271.

17. Carvalho, A. C. F. B.; Cortez, A. L. L.; Salotti, B. M.; Bürger, K .P.; Vidal-Martins, A .M. C. Arq. Inst. Biol. 2005, 72, 303.

18. Mattiuz, B. H.; Miguel, A. C. A.; Nachtigal, J. C.; Duriga, J. F.; Camargo, U. A. Rev. Bras. Frutic. 2004, 26.

19. Brasil. Ministério da Saúde. Agência Nacional de Vigilância Sanitária. RDC n ${ }^{\circ} 12$ de 02 de janeiro de 2001.

20. Arruda, M. C.; Jacomino, A. P.; Spoto, M. H. F.; Gallo, C. R.; Moretti, C. L. Ciênc. Tecnol. Aliment. 2004, 24, 53.

21. Silva Junior, E. A. Manual do controle higiênico-sanitário em alimentos. Varela: São Paulo, 4th ed., 1995.

22. Ponce, A. R.; Bastiani, M. I. D.; Minim, V. P.; Vanetti, M. C. D. Ciênc. Tecnol. Aliment. 2010, 30, 113.

23. Siqueira, R. S. Manual de microbiologia de alimentos. Embrapa: Brasília, Embrapa/CTAA: Rio de Janeiro, 1995.

24. Moraes, I. V. M. Morango processado minimamente e conservado sob refrigeração e atmosfera controlada. Dissertação (Mestrado em Engenharia Agrícola) Universidade Estadual de Campinas: Campinas. 2005.

25. Nascimento, M. S; Silva, N. Braz. J. Food Technol. 2010, 13, 11.

26. Brackett, R. E. Chapman \& Hall. 1994, 269.

27. Vitti, M. C. D; Kluge, R. A.; Gallo, C. R.; Schiavinato, M. A.;

Moretti, C. L.; Jacomino, A. P. Pesq. Agropec. Bras. 2004, 39, 1027.

\section{Amanda G. Guimarães ${ }^{1 *}$, Valter C. A. Júnior ${ }^{2 a}$, Cíntia G. Guimarães ${ }^{2 b}$, Tiago J. Guedes $^{2 c}$, Nísia A. V. D. Pinto}

\footnotetext{
${ }^{1}$ Universidade Estadual do Norte Fluminense Darcy Ribeiro. Departamento de Agronomia. Avenida Alberto Lamego, no 2000, Parque Califórnia, Campos dos Goytacazes, Rio de Janeiro, Brasil, CEP28013-602.

${ }^{2}$ Universidade Federal dos Vales do Jequitinhonha e Mucuri, Campus JK, Rodovia MGT 367 - Km 583, nº 5000, Alto da Jacuba CEP 39100000- Diamantina, Minas Gerais, Brasil.
}

*E-mail: amandagguimaraes@yahoo.com.br 